\title{
Approaches towards improving the quality of maternal and newborn health services in South Asia: challenges and opportunities for healthcare systems
}

Naeem uddin Mian ${ }^{1}$, Muhammad Adeel Alvi ${ }^{1}$, Mariam Zahid Malik', Sarosh lqbal ${ }^{1}$, Rubeena Zakar², Muhammad Zakria Zakar², Shehzad Hussain Awan', Faryal Shahid', Muhammad Ashraf Chaudhry' and Florian Fischer ${ }^{3^{*}}$ (D)

\begin{abstract}
Background: South Asia is experiencing a dismal state of maternal and newborn health (MNH) as the region has been falling behind in reducing the levels of maternal and neonatal mortality. Most of the efforts are focused on enhancing coverage of MNH services; however, quality remains a serious concern if the region is to achieve expected outcomes in terms of standardised MNH services within healthcare delivery systems. This research consists of a review of South Asian quality improvement (QI) approaches/interventions, specifically implemented for MNH improvement.

Methods: A literature review of QI approaches/interventions was conducted using the PRISMA guidelines. Online databases, including PubMed, the Cochrane Library and Google Scholar, were searched. Primary studies published between 1998 and 2013 were considered. Studies were initially screened and selected based upon the selection criteria for data extraction. A thematic synthesis/analysis was performed to organise, group and interpret the key findings according to prominent themes.

Results: Thirty studies from six South Asian countries were included in the review. Findings from these selected studies were grouped under eight broad, cross-cutting themes, which emerged from a deductive approach, representing the most commonly employed QI approaches for improving $\mathrm{MNH}$ services within different geographical settings. These consist of capacity building of healthcare providers on clinical quality, clinical audits and feedback, financial incentives to beneficiaries, pay-for-performance, supportive supervision, community engagement, collaborative efforts and multidimensional interventions.

Conclusions: Employing and documenting Ql approaches is essential in order to measure the potential of an intervention, considering its cost-effectiveness, feasibility and acceptability to communities. This research concluded that QI approaches are very diverse and cross-cutting, because they are subject to the varied requirements of regional health systems. This high level of variability leads to implementation and knowledge-management challenges for $\mathrm{MNH}$ programme planners and managers in the countries of the South Asia region.
\end{abstract}

Keywords: South Asia, Quality, Quality improvement, Maternal and newborn health

* Correspondence: f.fischer@uni-bielefeld.de

${ }^{3}$ Bielefeld University, School of Public Health, Bielefeld, Germany

Full list of author information is available at the end of the article

(c) The Author(s). 2018 Open Access This article is distributed under the terms of the Creative Commons Attribution 4.0 International License (http://creativecommons.org/licenses/by/4.0/), which permits unrestricted use, distribution, and reproduction in any medium, provided you give appropriate credit to the original author(s) and the source, provide a link to the Creative Commons license, and indicate if changes were made. The Creative Commons Public Domain Dedication waiver (http://creativecommons.org/publicdomain/zero/1.0/) applies to the data made available in this article, unless otherwise stated. 


\section{Background}

South Asian countries face huge public health challenges, particularly in maternal and newborn health (MNH) [1]. This is evident from the high infant mortality rates of India, Pakistan, Afghanistan, Bangladesh and Nepal [2, 3]. Hence, quality improvement (QI) in $\mathrm{MNH}$ care is a serious concern. It is evident that the process of QI requires sound local strategies in order to attain the best possible results by focusing on the need to optimise resource use and expand population coverage. It follows from this that increased expertise and resources will not, in themselves, translate into $\mathrm{MNH}$ care of high quality. This observation is supported by the fact that countries with the highest health spending are not always those with the highest quality healthcare system [4]. Quality improvement can be termed as a multidimensional concept, which draws upon several perspectives [5-7]. Initially, QI mainly concentrated on biomedical outcomes, however, over time its conceptualisation broadened and implied different meanings for varied stakeholders [7]. Patients view effectiveness of services, empathy, clean and safe environment and facilities as indicators of QI with special focus on readily access to the experienced and helpful provider, whereas healthcare providers regard efficacy of treatment, quality of care according to the clinical guideline as key QI intervention. Managers, on the other hand, emphasise client satisfaction and resource utilisation, while for policy makers, preference to access, cost, equity and effectiveness are the most critical attributes of quality improvement [7]. Thus, QI acknowledges the notion that quality must focus on optimum resource utilisation, using sound local strategies to address components pertaining to service users, patient satisfaction, sustainability and other aspects of healthcare $[8,9]$.

Over the past few decades, there has been a growing awareness of the need to improve quality across healthcare delivery, driven by the need to reduce inequalities and effectively translate evidence into practice alongside the changing expectations of patients and care-givers [10]. QI approaches to healthcare have been researched internationally; nevertheless, there is limited documentary evidence at a regional level in South Asia. For this reason, we carried out a review to document the various regional approaches and interventions, implemented to bring quality improvement in $\mathrm{MNH}$ services, particularly focusing on the achievement of the Sustainable Development Goal 3. The proposed research question for this review is to explore which key interventions/approaches have been applied for bringing QI in $\mathrm{MNH}$ services within the South Asian region.

\section{Materials and methods}

We adopted the quality assessment tool 'PRISMA', developed by the World Health Organisation (WHO), to perform the literature review [11] (Additional file 1).

\section{Eligibility}

We identified studies published between 1998 and 2013 in indexed national and international journals in the English language, focusing on QI approaches/interventions designed to improve $\mathrm{MNH}$ services in the regional countries of South Asia. Quality improvement interventions/approaches were defined as any systematic processes or actions aimed at reducing the quality gaps and leading to measurable improvements in $\mathrm{MNH}$ services and health status of the targeted populations $[12,13]$.

\section{Identification of studies}

We reviewed literature from academic databases, as well as project reports and documents. Key sources of electronic searches included reference libraries; namely, PubMed and the Cochrane Reference Libraries, along with Google Scholar. The goal was to access the available data on QI approaches for improving $\mathrm{MNH}$ services. While searching the databases, we employed various medical subject heading $(\mathrm{MeSH})$ search terms, such as 'maternal health, neonatal/newborn health, health services, and maternal welfare'. Other key terms included 'healthcare performance, interventions/approaches and quality improvement'. Our search strategies were then refined through the adoption of an iterative approach. In addition, a manual search was undertaken, consisting of the detailed examination of cross references and the bibliographies of selected publications to identify additional sources of information. The search was further widened to include a review of the grey literature of international and national organisations as well as development partners. The search comprised of both experimental and observational studies.

\section{Study selection}

Initially, we screened all the studies' titles and abstracts and repeated this process to ensure consistency. Studies were included in the review, which met one of the following criteria: 1) QI approaches/interventions with a primary focus on improving MNH services in South East Asian countries (including antenatal care, delivery care, postnatal care, neonatal care at birth, neonatal emergency care and neonatal primary care); or 2) QI approaches/interventions targeted at stakeholders including healthcare providers, health managers and beneficiaries for improving the $\mathrm{MNH}$ status of poor/ marginalised communities in the region. Furthermore, only those selected studies as per the above criteria were reviewed, where QI approaches/interventions have the potential for scaling-up. We excluded QI approaches that were not tested within the countries of South Asia.

\section{Data extraction}

We extracted data from all the studies identified, as fulfilling the above criteria. Two researchers independently 
reviewed the full text of these papers. A spreadsheet was used for data extraction. Finally, both researchers critically reviewed all the selected studies and resolved any observed inconsistencies through discussion. The data was extracted using the following parameters: 1) geographical setting and target population; 2) description of QI approaches/interventions and relevant set of services provided; 3) outcome; and 4) key findings, highlighting improved MNH services.

\section{Synthesis of results}

We adopted an analytical approach of thematic synthesis, in which data from selected studies was categorised, grouped and interpreted according to the prominent themes, with the aim of identifying common elements across the studies [14]. The analysis began with a deductive approach through which emerging themes and sub-themes were initially identified. All QI approaches/interventions implemented to improve $\mathrm{MNH}$ services were analysed, considering their quality measures, the strategies adopted, the main results and outcomes. Furthermore, they were grouped together to highlight key themes and summarised in tabular form (Additional file 2).

\section{Results}

The electronic database search yielded a large number of studies, which reflected the widespread discussion on QI approaches for improving $\mathrm{MNH}$ services. A total of 2613 unique records were retrieved, out of which 156 full texts were screened. Finally, 30 studies on QI approaches/interventions were selected for analysis from six South Asian countries: Afghanistan, Bangladesh, India, Nepal, Pakistan and Sri Lanka. In Fig. 1, the flow of studies through searching and screening for inclusion is described.

\section{Quality improvement approaches/interventions}

The analysis of selected studies highlighted eight broad cross-cutting themes as the most commonly applied QI approaches/interventions for improving quality of care in the South Asian region. Nine studies focused building the capacities of healthcare providers in clinical quality, two in clinical audits and feedback, two discussed providing financial incentives, one each highlighted improvements in health workers' performance, efficiency through pay-for-performance schemes and supportive supervision, eight studies dealt with community engagement, four elucidated collaborative efforts or public/

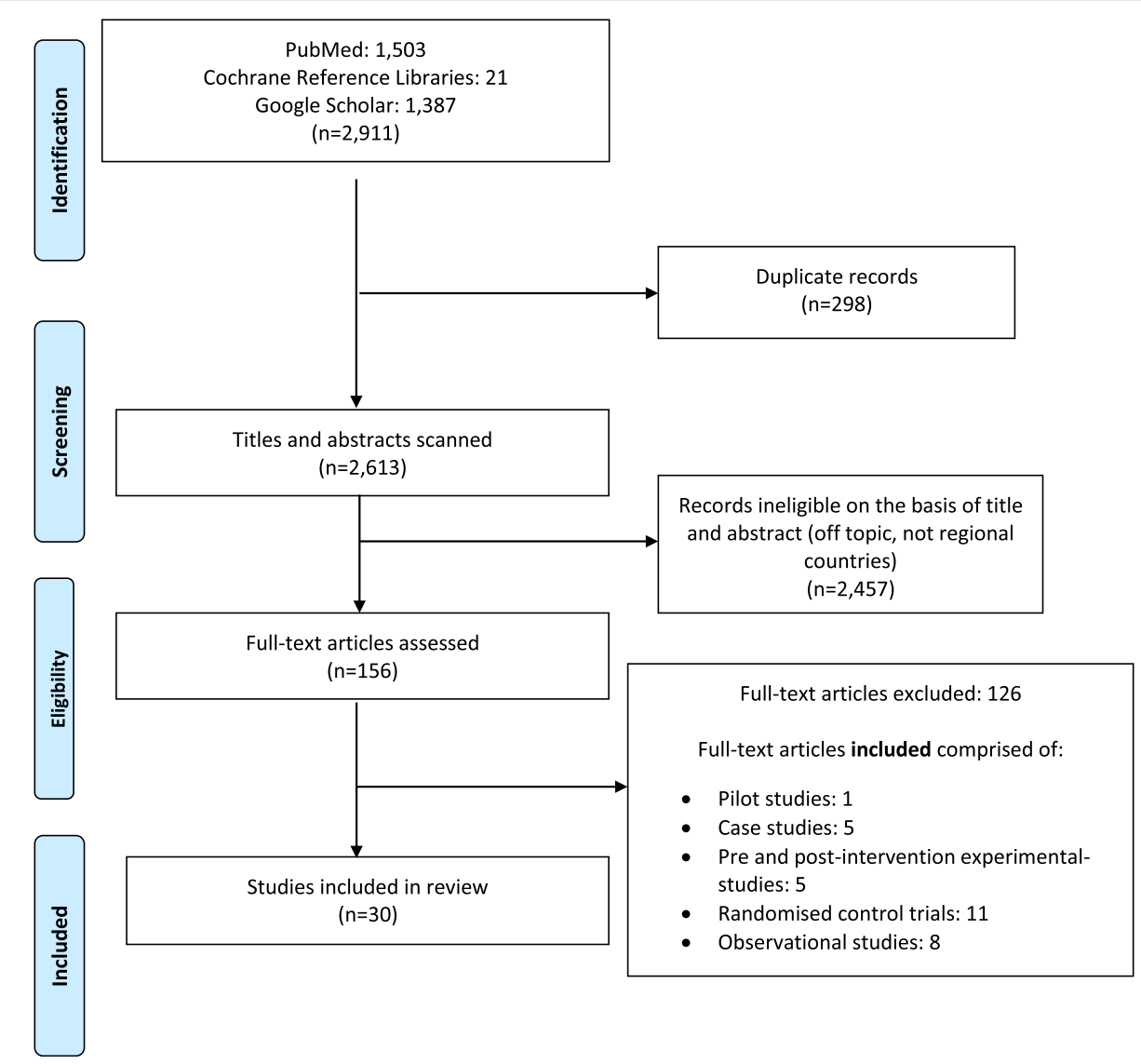

Fig. 1 PRISMA flow chart for study selection 
private partnerships and the remaining two addressed multidimensional interventions.

\section{A) Capacity building of healthcare providers in clinical quality} Capacity building of healthcare providers (HCPs) on improvements in quality of care, knowledge level, adherence to clinical protocols and changes in clinical practice behaviour was adopted as a proven QI approach to improve the quality of $\mathrm{MNH}$ services. The results indicated that most of the studies focused on the capacity building of Traditional Birth Attendants (TBAs) for delivery assistance, particularly in the use of delivery kits, enhanced referrals and linkage with community health workers as a key QI approach. Evidence from Pakistan showed a 31\% reduction in stillbirths, $29 \%$ in the neonatal mortality rate (NMR) and 39\% in haemorrhage-related complications during pregnancy, along with a $50 \%$ increase in referrals for emergency obstetric care, after deploying TBAs in communities for perinatal care $[15,16]$. Similarly, an investigation into the training of TBAs on clean delivery kits revealed that trained TBAs were twice as likely to perform a clean delivery in rural Bangladesh. However, evidence was lacking to support the positive effect of training TBAs in the occurrence of maternal infections [17]. The findings revealed that training HCPs in antenatal care (ANC), routine visits, regular intake of vitamin supplements, recognition of danger signs, and measures for intermittent preventive treatment during pregnancy and postnatal care showed comparatively better results in utilisation of $\mathrm{MCH}$ services. Furthermore, after building capacity on the integrated management of childhood illnesses (IMCI), a significant reduction was observed in the incidences of malaria, pneumonia and diarrhoea amongst children in comparison to other areas [18].

Multiple studies showed that training in emergency newborn care has improved newborn health outcomes in regional countries like Sri Lanka, Bangladesh, India and Pakistan. Various QI approaches/interventions were applied to promote the practices of thermal protection, preventing asphyxia, preparedness for resuscitation and neonatal assessment, along with the management of low birth weight, respiratory distress, feeding and neonatal sepsis [19-22].

\section{B) Clinical audits and feedback}

Clinical audit and feedback is a proven QI approach, involving the systematic critical analysis of the quality of clinical care given to patients, focusing on such factors as procedures used for diagnosis and treatment, use of resources and outcome [23]. Our findings indicated that audits of clinical practice, maternal audits and the development and implementation of guidelines have added value to clinical performance, service utilisation and patient satisfaction [24]. Moreover, the use of quality scorecards at health facilities and their dissemination to communities were some of the diverse methods implemented for improving the quality of clinical services [25].

\section{C) Financial incentives for beneficiaries}

The provision of free-of-cost services or financial incentives for beneficiaries as QI approaches/interventions were found to be successful strategies, resulting in improved service utilisation and user satisfaction. A study conducted in Nepal examined the provision of free maternity care through reimbursement to facilities from government funds for facility-based deliveries. The results showed a substantial increase in facility-based deliveries, management of complications and caesarean sections. Furthermore, beneficiaries experienced minimal delays in receiving care at these facilities [26]. Meanwhile, maternal health voucher programmes specifically targeted at safe deliveries have expanded in Bangladesh, India and Nepal [27]. These vouchers increased the number of deliveries taking place at health facilities [28]. Social protection mechanisms in the form of insurance cover for obstetric risks implemented in India increased the average number of ANC visits and ultrasound examinations during ANC visits [18].

\section{D) Pay-for-performance}

Improving the performance of HCPs through pay-forperformance is a continuous QI approach designed to deliver the best services. Providing performance-based payments to HCPs under the Accredited Social Health Activists (ASHAs) programme in India led to an increase in both facility-based deliveries and breastfeeding practices, as well as a decline in neonatal mortality of up to $70 \%[29,30]$. Moreover, in Pakistan under the Chief Minister's initiative for the attainment and realisation of MDGs (CHARM), all staff members, from medical officers to drivers and security guards, were incentivised to encourage facility-based deliveries [31].

\section{E) Supportive supervision}

Supportive supervision is a facilitative approach of supervision, providing necessary leadership and support for QI and emphasizing mentorship, joint problem solving and two-way communication between supervisors and those being supervised [32]. Supportive supervision is an optimal QI approach for clinical settings as it overturns traditional notions of supervision and focuses on facilitation rather than inspection [32]. Overall, supportive supervision of $\mathrm{HCPs}$ within the health system demonstrated better $\mathrm{MNH}$ outcomes and augmented motivation. This is evident in an example of supervisory strategy adopted by the Bangladesh Rural Advancement Committee (BRAC) Shasthya Shebikas, in which strong supervision was provided for community health workers (CHWs) from other CHWs with a 
higher level of training (Shasthya Kormis). Unlike traditional health professionals, these supervisors were found to be fully capable of performing their duties within their community and improving $\mathrm{MNH}$ outcomes [33-35].

\section{F) Community engagement}

Studies highlighting community engagement mainly focused on mothers' education in birth preparedness, the optimum number of ANC visits, recognition of danger signs and newborn care. The results showed a raised awareness and increased utilisation of $\mathrm{MNH}$ services in countries in the region [36, 37]. However, no significant effect on mortality was observed, except in a few areas of Bangladesh where neonatal mortality significantly decreased with the introduction of these practices and the resulting enhanced knowledge about maternal and neonatal danger signs [38]. A comprehensive process of participatory learning and an action cycle also implemented in Bangladesh showed no effect on maternal or newborn mortality [39]. Another example of community engagement included regular visits by trained midwives to the community for counselling, which significantly increased the initiation of breastfeeding in Bangladesh and contraceptive uptake by women in Pakistan and Nepal [40-42]. Moreover, behavioural change communication addressing lactation and contraception in rural areas of India not only increased knowledge of the lactational amenorrhea method but also promoted birth spacing [43].

\section{G) Collaborative efforts/contracting out}

Collaborative efforts included public/private partnerships (PPPs): contracting out arrangements between government and private entities for the provision of $\mathrm{MNH}$ services, such as infrastructure, equipment, human resources or technical health services [44]. The findings indicated that delays in treating obstetric emergencies leading to maternal mortality were reduced in rural areas of Pakistan and Bangladesh with the provision of ambulances, the meeting of associated expenses and a referral system [44, 45]. An example from Uttar Pradesh, India, highlighted the provision of contraceptives at subsidised rates for distribution and sale to private providers, which increased the availability of contraceptives in the state [46]. Similarly, the government of Afghanistan, in collaboration with international partners and government and non-government organisations, designed a Basic Package of Health Services (BPHS) for the provision of $\mathrm{MNH}$ services to its rural population. Following this intervention, BPHS facilities increased from 1075 in 2004 to 1829 in 2011. Thus, there was an overall increase in attended births [47].

\section{H) Multidimensional interventions}

Multidimensional QI approaches included those studies considering a combination of two or more strategies, implemented within large-scale programmes aimed at improving $\mathrm{MNH}$ outcomes. Facility upgrading (infrastructure, equipment, drugs and supplies) was seen as the most common QI approach, coupled with other integrated approaches, such as staff training, monitoring and supervision, strengthening of the referral system, the use of audits and guidelines, contracting out, improved data management and logistic support [48]. For example, the quality of ANC services was increased in rural India by ensuring the provision of necessary equipment, focused training and the reorganisation of outreach services. The findings showed that the delivery of special preventive packages comprising essential newborn care (ENC) service workers resulted in improving birth preparedness and delivery outcomes, with enhanced breastfeeding practices in Shivgarh India [49].

\section{Discussion}

This review aimed to identify QI approaches/interventions with proven effects on upgrading the $\mathrm{MNH}$ services implemented in countries of the South Asian region. QI approaches in healthcare settings usually target one or more of the following three groups: health managers, healthcare providers and end-users/beneficiaries. This review considered all of these perspectives, while primarily focusing on improved MNH outcomes from the beneficiaries' point of view, which is still rarely considered in many settings [50].

The overall findings revealed mixed evidence, involving various cross-cutting QI approaches being employed to improve $\mathrm{MNH}$ services with varying level of success. It revealed that the most effective QI approaches are carefully rationalised, considering the needs of the target population, the socio-cultural context and the quality of healthcare services. Moreover, the knowledge and motivation of healthcare providers, as well as their interactions with clients and supportive supervision, also boost their performance.

Capacity building of HCPs in the area of clinical quality was found to be the most common QI approach within low-resource settings, in contrast to other QI approaches where extensive financial inputs are involved. Regional evidence revealed that strengthening the capacity of HCPs, particularly TBAs and CHWs, is an effective approach to reducing MNH morbidity and mortality [51, 52]. The situation is similar for countries such as Pakistan, India and Bangladesh, where most deliveries are conducted by TBAs, who require continuous support in the form of training and referral to save mothers and children [53, 54].

The studies showed that clinical audits and feedback mechanisms have a significant effect on case fatality rates and maternal mortality. They also indicated that the implementation of referral guidelines [23] and the dissemination of performance indicators via scorecards 
[24] incorporated elements of an evaluation-action cycle for developing strategies for QI. The improvements outlined were significantly associated with participatory methodologies involving service providers and facility management [25].

The provision of financial incentives and supportive supervision was significantly associated with improved $\mathrm{MNH}$ outcomes. Regional evidence suggests that monetary incentives for beneficiaries and rewarding HCPs for better performance both lead to an improvement in MNH outcomes [26, 27]. Quality of care was reported as a concern of the poor and disadvantaged. Therefore, strategies centred around reducing out-of-pocket expenditure through targeted subsidies and risk insurance leads to improvements in service uptake by the poorest quintile [36, 37]. Moreover, the upgrading of facilities through improvements in infrastructure, equipment, drugs and supplies was also seen as a significant QI approach, in areas where sufficient resources and financial commitment is available [31, 32]. Such findings have significant linkages with the situation of low-middleincome countries in South Asia as facility readiness in this region was documented to be far below acceptable levels, particularly at public facilities [54].

It seems that service uptake tends to increase when strategies are mainly focused on patient perceptions. Interventions such as awareness-raising sessions led to an increased utilisation of ANC services and greater client satisfaction, and meant that patients were more likely to refer new women to the facility than those receiving care from TBAs $[35,52]$. Furthermore, assigning a designated service provider during the entire process of pregnancy and the postnatal period increased the utilisation of services and improved continuity of care [36-38]. Exposure to contraceptive counselling and educational visits by trained midwives not only led to a significant increase in contraceptive knowledge and uptake, but also resulted in the more frequent practice of birth spacing [39-41]. Collaborative efforts aimed at health education and the provision of medical supplies at subsidised rates went on to produce desirable results [44].

\section{Limitations}

The majority of studies included in this review were based on intervention impact assessments rather than surveys or interviews, which adds to its consistency. However, this paper only highlights the different interventions and their outcomes without assigning any weights to the effectiveness of each implementation. Certain significant studies in further languages were not incorporated into the data synthesis, considering the review was limited to three databases and English language only. This may be considered a substantial limitation of this review. In addition, some significant studies with regional representation could not be included due to open-access issues, particularly for Bhutan and the Maldives.

\section{Conclusion}

The QI approach is key to improving equity in $\mathrm{MNH}$ service delivery. Our research concluded that QI approaches are diverse and cross-cutting and subject to the varied requirements of regional health systems. This review reflects that there is a high level of variability of QI approaches, subject to the selection of any QI intervention, considering the varied needs of stakeholders within particular geographical context, leading to implementation and knowledge management challenges for $\mathrm{MNH}$ programme planners and managers in countries within the region.

Employing and documenting QI approaches is essential in order to measure the potential of each intervention, considering its cost-effectiveness, feasibility and acceptability to communities. Summarising the above, the process of quality improvement does not end with implementation. It requires extensive and continuous efforts, resources and technical expertise. Ultimately, QI approaches to improving $\mathrm{MNH}$ services are only viable if they are sustainable and integrated into the health systems, paving the way to attaining sustainable development goals in the region, particularly for improving health status, promoting well-being and reducing maternal and newborn mortality.

\section{Additional files}

Additional file 1: PRISMA 2009 Checklist. (DOC 66 kb)

Additional file 2: Description of reviewed studies disaggregated by QI interventions. (DOCX $39 \mathrm{~kb}$ )

\section{Abbreviations}

ANC: Antenatal care; ASHA: Accredited Social Health Activists; BPHS: Basic Package of Health Services; BRAC: Bangladesh Rural Advancement Committee; CHARM: Chief Ministers initiative for the attainment and realization of MDGs; CHWs: Community health workers; EmOC: Emergency obstetric care; HCPS: Health care providers; IMCI: Integrated management of childhood illness; MeSH: Medical subject headings; MNH: Maternal and newborn health; NMR: Neonatal mortality rate; PNC: Post-natal care; PPP: Public private partnerships; QI: Quality improvement; TBAs: Traditional Birth Attendants; WHO: World Health Organization

\section{Acknowledgements}

We acknowledge support of the publication fee by Deutsche Forschungsgemeinschaft and the Open Access Publication Funds of Bielefeld University.

Funding

The study received no funding.

Availability of data and materials

This research is based on a literature review. A summary is provided in the Additional files. 


\section{Authors' contributions}

NM has been involved in conceiving the concept and revising the manuscript critically. AA carried out the QI study and participated in the design of the manuscript. MZM and SI drafted the manuscript. RZ and MZZ made substantial contribution in conception, design, analysis and interpretation of findings. SHA and FS participated in the design and analysis for the manuscript. AC contributed in finalizing results for manuscript. FF contributed intellectual content during the manuscript preparation. All authors read the final manuscript.

\section{Ethics approval and consent to participate}

Not applicable.

\section{Consent for publication}

Not applicable.

\section{Competing interests}

The authors declare that they have no competing interests.

\section{Publisher's Note}

Springer Nature remains neutral with regard to jurisdictional claims in published maps and institutional affiliations.

\section{Author details}

${ }^{1}$ Contech International, Lahore, Pakistan. ${ }^{2}$ Institute of Social and Cultural Studies, Lahore, Pakistan. ${ }^{3}$ Bielefeld University, School of Public Health, Bielefeld, Germany.

\section{Received: 2 February 2017 Accepted: 26 January 2018}

\section{Published online: 06 February 2018}

\section{References}

1. Haté V, Gannon S. Public health in South Asia: a report of the CSIS Global Health policy center. Washington, DC: Center for Strategic and International Studies; 2010.

2. WHO, UNICEF, UNFPA, World Bank. Trends in maternal mortality: 1990 to 2015. Geneva: World Health Organization; 2015.

3. WHO, UNICEF, UNFPA, World Bank. Trends in child mortality: 1990 to 2015 Geneva: World Health Organization; 2015.

4. Leatherman S, Sutherland K. Quality of care in the NHS of England. BMJ. 2004;328:288-90.

5. Grimmer K, Sheppard L, Pitt M, Magarey M, Trott P. Differences in stakeholder expectations in the outcome of physiotherapy management of acute low back pain. Int J Qual Health Care. 1999:11:155-62.

6. Dawda P, Jenkins R, Varnam R. Quality improvement in general practice. Discussion paper. London: The King's Fund; 2010.

7. Kerssens JJ, Groenewegen PP, Sixma HJ, Boerma WW, van der Eijk I. Comparison of patient evaluations of health care quality in relation to WHO measures of achievement in 12 European countries. Bull World Health Organ. 2004;82(2):106-15.

8. Pitroff R, Campbell O. Quality of maternity care: silver bullet or red herring? London: London School of Hygiene and Tropical Medicine; 2000.

9. Bruce J. Fundamental elements of the quality of care: a simple framework. Stud Fam Plan. 1990;21(2):61-91.

10. Donabedian A. The quality of care. How can it be assessed? JAMA. 1988; 260:1743-8.

11. Moher D, Liberati A, Tetzlaff J, Altman DG, The PRISMA Group. Preferred reporting items for systematic reviews and meta-analyses: the PRISMA statement. Open Med. 2009:3(3):123-30.

12. WHO. How quality improvement in health care can help to achieve the millennium development goals. Bull World Health Organ. 2006;84(4):257-336.

13. U.S. Department of Health and Human Services. Quality Improvement. Washington: U.S. Department of Health and Human Services; 2011.

14. Lucas PJ, Baird J, Arai L, Law C, Roberts HM. Worked examples of alternative methods for the synthesis of qualitative and quantitative research in systematic reviews. BMC Med Res Methodol. 2007;7:4.

15. Jokhio AH, Winter HR, Cheng KK. An intervention involving traditional birth attendants and perinatal and maternal mortality in Pakistan. N Engl J Med. 2005;352(20):2091-9
16. Bhutta ZA, Memon ZA, Soofi S, Salat MS, Cousens S, Martines J. Implementing community-based perinatal care: results from a pilot study in rural Pakistan. Bull World Health Organ. 2008;86(6):452-9.

17. Goodburn EA, Chowdhury M, Gazi R, Marshall T, Graham W. Training traditional birth attendants in clean delivery does not prevent postpartum infection. Health Policy Plan. 2000;15:394-9.

18. Barua A, Waghmare R, Venkiteswaran S. Implementing reproductive and child health services in rural Maharashtra, India: a pragmatic approach. Reprod Health Matters. 2003;11:140-9.

19. Senarath U, Fernando DN, Rodrigo I. Effect of training for care providers on practice of essential newborn care in hospitals in Sri Lanka. J Obstet Gynecol Neonatal Nurs. 2007;36:531-41.

20. Arifeen SE, Hoque DME, Akter T, Rahman M, Hoque ME, Begum K, Chowdhury EK, Khan R, Blum LS, Ahmed S, Hossain MA, Siddik A, Begum N, Sadeq-ur Rahman Q, Haque TM, Billah SM, Islam M, Rumi RA, Law E, Al-Helal ZA, Baqui AH, Schellenberg J, Adam T, Moulton LH, Habicht JP, Scherpbier RW, Victora CG, Bryce J, Black RE. Effect of the integrated management of childhood illness strategy on childhood mortality and nutrition in a rural area in Bangladesh: a cluster randomised trial. Lancet. 2009:374:393-400.

21. Tholpadi S, Sudhindra B, Bhutani V. Neonatal resuscitation program in rural Kerela India to reduce infant mortality attributed to perinatal asphyxia. J Perinatol. 2000;20:46.

22. Mufti $P$, Setna F, Nazir K. Early neonatal mortality: effects of interventions on survival of low birth babies weighing 1000-2000g. Pak Med Assoc. 2006;56(4):174-6.

23. NHS Trust. Improving Patient Care through Clinical Audit - A How to Do Guide. Dartforf: Dartford and Gravesham, NHS Trust; 2017.

24. Chowdhury EK, El Arifeen S, Rahman M, Hoque DE, Hossain MA, Begum K, Siddik A, Begum N, Sadeq-ur Rahman Q, Akter T, Haque TM, Al-Helal ZM, Baqui AH, Bryce J, Black RE. Care at first-level facilities for children with severe pneumonia in Bangladesh: a cohort study. Lancet. 2008;372:822. J Pak Med Assoc 30

25. Khan MMR, Hotchkiss D, Dmytraczenko T, Zunaid AK. Use of a balanced scorecard in strengthening health systems in developing countries: an analysis based on nationally representative Bangladesh health facility survey. Int J Health Plann Mgmt. 2013:28:202-15.

26. Witter $\mathrm{S}$, Khadka S, Nath $\mathrm{H}$, Triwari S. The national free delivery policy in Nepal: early evidence of its effects on health facilities. Health Policy Plan 2011;26(Suppl. 2):ii84-91.

27. Eichler R, Agarwal K, Askew I, Iriarte E, Morgan L, Watson J. Performancebased incentives to improve health status of mothers and newborns: what does the evidence show? J Health Popul Nutr. 2013;31(4 Suppl. 2):36-47.

28. Bellows BW, Conlon CM, Higgs ES, Townsend JW, Nahed MG, Cavanaugh K, Grainger CG, Okal J, Gorter AC. A taxonomy and results from a

comprehensive review of 28 maternal health voucher programmes. J Health Popul Nutr. 2013;31(4 Suppl. 2):106-28.

29. Paul V, Sanchez H, Mavalankar D, Ramachandran P, Sankar M, Bhandari N, Sreenivas V, Sundararaman T, Govil D, Osrin D, Kirkwood B. Reproductive health, and child health and nutrition in India: meeting the challenge. Lancet. 2011;377(9762):332-49.

30. Lim S, Dandona L, Hoisington J, James S, Hogan M, Gakidou E. India's Janani Suraksha Yojana, a conditional cash transfer programme to increase births in health facilities: an impact evaluation. Lancet. 2010:375(9730):5-11.

31. UNICEF. Innovative approaches to maternal and newborn health. Compendium of case studies. New York: United Nations Children's Fund; 2013.

32. Marquez $L$, Kean L. Making supervision supportive and sustainable: new approaches to old problems, maximizing access and quality initiative. MAQ paper no. 4 2002. Washington, DC: USAID; 2002.

33. Ahmed SM. Taking healthcare where the community is: the story of the Shasthya Sebikas of BRAC in Bangladesh. BRAC University J. 2008;1:39-45.

34. Ahmed F. Community empowerment through micro-finance to improve community health: BRAC's experience in Bangladesh. 6-8 August 2008. WHO/SEARO Regional Conference on Revitalizing Primary Health Care. Jakarta: WHO/SEAR; 2008.

35. BRAC Health, Nutrition and Population programme at a glance as of December 2014. BRAC. https://brac.net/health-nutrition-population/item/ 863-overview. Accessed 25 Jan 2017.

36. Dongre AR, Deshmukh PR, Garg BS. A community-based approach to improve health care seeking for newborn danger signs in rural Wardha, India. Indian J Pediatr. 2009;76:45-50. 
37. Mcpherson RA, Khadka N, Moore JM, Sharma M. Are birth-preparedness programmes effective? Results from a field trial in Siraha district, Nepal. J Health Popul Nutr. 2006;24:479-88.

38. Fottrell E, Azad K, Kuddus A, Younes L, Shaha S, Nahar T, Aumon BH, Hossen M, Beard J, Hossain T, Pulkki-Brannstrom AM, Skordis-Worrall J, Prost A, Costello A, Houweling TA. The effect of increased coverage of participatory women's groups on neonatal mortality in Bangladesh: a cluster randomized trial. JAMA Pediatr. 2013;167(9):816-25.

39. Darmstadt GL, Choi Y, Arifeen SE, Bari S, Rahman SM, Mannan I, Seraji HR, Winch PJ, Saha SK, Ahmed AS, Ahmed S, Begum N, Lee AC, Black RE, Santosham M, Crook D, Baqui AH, Bangladesh Projahnmo-2 Mirzapur Study Group. Evaluation of a cluster-randomized controlled trial of a package of community-based maternal and newborn interventions in Mirzapur, Bangladesh. PLoS One. 2010;5(3):e9696.

40. Azad K, Barnett S, Banerjee B, Shaha S, Khan K, Rega AR, Barua S, Flatman D, Pagel C, Prost A, Costello A. The effect of scaling up women's groups on birth outcomes in three rural districts of Bangladesh: a cluster- randomised controlled trial. Lancet. 2010;475:1193-202.

41. Saeed GA, Fakhar S, Rahim F, Tabassum S. Change in trend of contraceptive uptake - effect of educational leaflets and counselling Contraception. 2008;77(5):377-81.

42. Bolam A, Manandhar DS, Shrestha P, Ellis M, Costello AM. The effects of postnatal health education for mothers on infant care and family planning practices in Nepal: a randomised controlled trial. BMJ. 1998;316:805-11.

43. Sebastian MP, Khan ME, Kumari K, Idnani R. Increasing postpartum contraception in rural India: evaluation of a community-based behaviour change communication intervention. Int Perspect Sex Reprod Health. 2012;38(2):68-77.

44. Paiman. Review of public private partnerships models. Islamabad: Pakistan Initiative for Mothers and Newborns; 2006.

45. Midhet F. Final report - safe motherhood initiative in rural Balochistan Karachi: The Asia Foundation; 1998

46. Global Health Technical Assistance Project. Expanding access and demand for DMPA in Uttar Pradesh, Jharkhand, and Uttarakhand. Washington: Global Health Technical Assistance Project; 2009.

47. Newbrander W, Ickx P, Feroz F, Stanekzai H. Afghanistan's basic package of health services: its development and effects on rebuilding the health system. Global Public Health. 2014;9(Suppl 1):6-28.

48. Rana TG, Chataut BD, Shakya G, Nanda G, Pratt A, Sakai S. Strengthening emergency obstetric care in Nepal: the Women's right to life and health project (WRLHP). Int J Gynaecol Obstet. 2007;98:271-7.

49. Kumar V, Mohanty S, Kumar A, Misra RP, Santosham M, Awasthi S, Baqui AH, Singh P, Singh V, Ahuja RC, Singh JV, Malik GK, Ahmed S, Black RE, Bhandari M, Darmstadt GL, Saksham Study Group. Effect of community-based behaviour change management on neonatal mortality in Shivgarh, Uttar Pradesh, India: a cluster-randomised controlled trial. Lancet. 2008;372:1151-62

50. Lancet Global Health blog. The role of quality improvement in maternal and newborn health beyond 2015. http://globalhealth.thelancet.com/2014/ 11/07/role-quality-improvement-maternal-and-newborn-health-beyond2015. Accessed 25 Jan 2017.

51. O'Rourke K. The effect of hospital staff training on management of obstetrical patients referred by traditional birth attendants. Int J Gynecol Obstet. 1995;48:95-102.

52. Sarker BK, Rahman M, Rahman T, Hossain J, Reichenbach L, Mitra DK. Reasons for preference of home delivery with traditional birth attendants (TBAs) in rural Bangladesh: a qualitative exploration. PLoS One. 2016;11(1):e0146161.

53. Shah N, Rohra DK. Home deliveries: reasons and adverse outcomes in women presenting to a tertiary care hospital. J Pak Med Assoc. 2010;60(7):555-8.

54. Technical Resource Facility. Health Facility Assessment - Pakistan National Report; 2012.

\section{Submit your next manuscript to BioMed Central and we will help you at every step:}

- We accept pre-submission inquiries

- Our selector tool helps you to find the most relevant journal

- We provide round the clock customer support

- Convenient online submission

- Thorough peer review

- Inclusion in PubMed and all major indexing services

- Maximum visibility for your research

Submit your manuscript at www.biomedcentral.com/submit
) Biomed Central 